\title{
Los inicios de un debate interminable: la cuestión del origen de los Campos Elisios en la filología de la Antigüedad
}

\author{
Miguel Rodríguez-Díaz¹, Germán Santana Henríquez²
}

Recibido: 30 de noviembre de 2017 / Aceptado: 2 de febrero de 2018

Resumen. Desde el siglo XIX asistimos a un intenso debate acerca de los Campos Elisios, centrado en una cuestión fundamental: su origen. Aún hoy, la discusión permanece abierta, a pesar de que se han planteado multitud de explicaciones y se han implicado los mejores expertos. El propósito de este trabajo es demostrar que esta cuestión fue ya planteada por los filólogos de la Antigüedad. Mediante la recopilación y estudio de todos los testimonios supervivientes, se intenta reconstruir los principales aspectos de la discusión, desde los investigadores implicados a las metodologías utilizadas y los resultados alcanzados. El estudio persigue poner de relieve las múltiples conexiones entre ambos debates, el antiguo y el moderno.

Palabras clave: Campos Elisios (origen y etimología), filología griega de la Antigüedad, filología y lexicografía bizantina.

\section{[en] The beginnings of a never-ending debate: the origin of Elysium in ancient scholarship}

\begin{abstract}
From the XIXth century on, there has been an extensive debate about Elysium, focused on a fundamental issue: its origin. Still today, the discussion remains wide open, although many explanations have been offered and most of the leading experts have had their say. Our primary objective is to expose that the issue was already addressed by Greek and Roman scholarship. By collecting and studying all extant remains, we attempt to reconstruct the main aspects of the discussion; researchers, methods, explanations. The study is intended to highlight the multiple conexions between both debates, ancient and modern.
\end{abstract}

Keywords: Elysium (origin and etymology), Ancient Greek Scholarship, Byzantine philology and lexicography.

Sumario. 1. Lexicon atribuido a Nicéforo Gregoras (s. XIV d.C.). 2. Etymologicum Magnum (s. XII d.C.). 3. Eustacio de Tesalónica (s. XII d.C.). 4. Léxico Suda (s. X d.C.). 5. Lexicum Gudianum (s. X d.C.). 6. Léxico Haimodein (s. IX-X d.C.). 7. Escolios antiguos (s. IX-XI d. C.). 8. Pseudo-Nonno (s. VI d.C.). 9. Hesiquio (s. V-VI a.C.). 10. Estobeo (s. V d.C.), cita de Porfirio de Tiro. 11. Orígenes (s. IV d.C.). 12. Servio (s. IV d.C.).

Cómo citar: Rodríguez-Díaz, M.; Santana Henríquez, G. (2018) Los inicios de un debate interminable: la cuestión del origen de los Campos Elisios en la filología de la Antigüedad, en Cuadernos de Filología Clásica. Estudios griegos e indoeuropeos 28, 267-280.

\footnotetext{
Universidad de Las Palmas de Gran Canaria. E-mail: miguel.rodriguez@ulpgc.es

$2 \quad$ Universidad de Las Palmas de Gran Canaria. E-mail: german.santanahenriquez@ulpgc.es
} 
Desde finales del siglo XIX hasta hoy se ha generado una gran producción científica en torno a los Campos Elisios. El interés del tema es comprensible, si tenemos en cuenta el papel tan destacado que este espacio mítico desempeña, ya no solo en la propia cultura grecolatina, sino también en toda la tradición posterior. Sin embargo, el volumen de dicha producción oculta un hecho un tanto sorprendente (y, desde luego, menos comprensible) y es que el estudio de los Campos Elisios tiende a centrarse en una única cuestión: su origen. Una somera revisión de la bibliografía muestra que los investigadores parecen perseguir siempre como principal objetivo remontarse hasta la fons et origo de este paraíso mitológico; y que, además, para tal fin todos coinciden en adoptar una metodología similar, que consiste, esencialmente, en tratar de desvelar el secreto de su misterioso nombre (en griego, $\tau$ ò $\pi \varepsilon \delta$ íov, lit. la llanura elisia), lo que implica esclarecer de dónde viene ese enigmá-

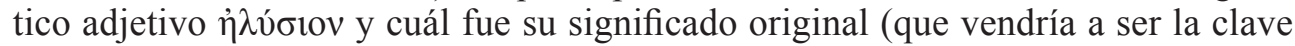
de la investigación).

Dado que no solo el nombre del espacio mítico resulta peculiar, sino que además con él se designa una concepción del más allá relativamente marginal durante los primeros siglos de la literatura griega (con una única y escueta aparición en el canto IV de la Odisea, y otra, muy parecida, en el canto IV de las Argonáuticas de Apolonio de Rodas, en un pasaje de clara reminiscencias homéricas), no es de extrañar que abunden las explicaciones que contemplan el término y el concepto como una especie de cuerpo extraño, bien por tratarse de un arcaísmo bien de una innovación. Así, dentro de los partidarios de la primera opción hay quienes prefieren considerar que proviene de la herencia ancestral indoeuropea (de *welnutiyom pedíom, lit. la 'llanura herbosa', una pradera del paisaje de ultratumba $\left.{ }^{3}\right)$, mientras para otros sería un resto del sustrato prehelénico (relacionado con nombres pregriegos como Ilitía y Eleusis $^{4}$ ); para los de la segunda, se han aducido diversos préstamos desde diferentes culturas circundantes, entre las que destacan los pueblos semitas de Asia Menor y Mesopotamia (p.ej. del nombre del dios supremo ugarítico Elu ${ }^{5}$ ), y sobre todo, los egipcios (de otra pradera de ultratumba, el sekhet ialu, lit 'Campo de las Juncias'6). No faltan tampoco propuestas más complejas que invocan la interacción de varios de estos factores (p. ej. la idea clásica de Nilsson 7 , que lo consideraba un producto de la influencia egipcia sobre las culturas minoica y micénica). Sin embargo, otros autores han ofrecido explicaciones en una línea bien distinta, acudiendo a la idea de un desarrollo interno de la propia religión helénica y estableciendo, en consonancia, una derivación a partir del griego: es el caso de las hipótesis, muy exitosas, de que la llanura elisia significaba, en origen, la 'llanura del irse' $(<* \dot{\varepsilon} \lambda v \theta-)^{8}$ o la 'llanura sagrada'

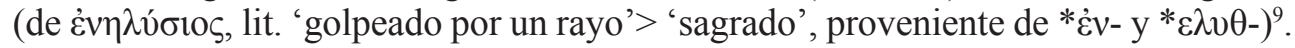

Como puede verse, en este tipo de explicaciones la etimología juega un papel fundamental, ya que se convierte en la prueba final y definitiva de todo el proceso de argumentación. En consecuencia, el número total de etimologías propuestas va creciendo sin cesar con cada nuevo intento de los investigadores, hasta desembocar

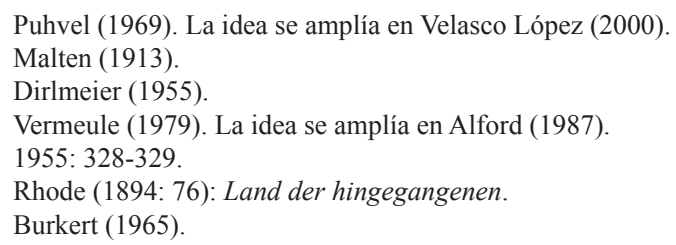


en una situación posiblemente única en el panorama de la lexicografía griega: pocas palabras podrían competir con esta en cantidad de etimologías aducidas (además de la media docena aquí reseñadas, existen otras diez o quince de menor aceptación, lo que supone una cifra total en torno a la veintena ${ }^{10}$ ). Por desgracia, el caso es que ninguna resulta, hasta el momento, lo suficientemente concluyente como para imponerse a todas las demás, ya que incluso las mejor fundamentadas han recibido objeciones de mucho peso. Si bien es cierto que algunas gozan de mayor crédito que otras, las preferencias de los estudiosos parecen ir siempre cambiando con el tiempo, evolucionando al ritmo de sucesivas aportaciones, y cuando alguna parece darse por definitivamente aceptada, siempre surge otra diferente en el terreno de competición $^{11}$. Como resultado, el estado actual de la cuestión del origen de los Campos Elisios es a la vez confuso y descorazonador: sería difícil encontrar otro espacio mítico grecolatino que haya recibido tantas y tan variadas explicaciones, explorando todas y cada una de las posibilidades históricas concebibles (herencia, sustrato, préstamo, creación propia) e implicando en la discusión a muchas grandes figuras de nuestra

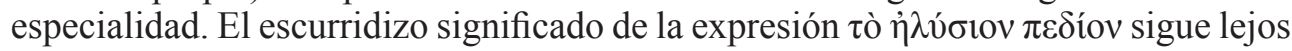
de aclararse, y la única certeza es que el debate acerca de la cuestión, convertido ya en una interminable controversia de más de un siglo de duración, ha proseguido hasta hoy, sin que sepamos aún a ciencia cierta ni de dónde vienen los Campos Elisios, ni cuál es el sentido original de su denominación.

Ante una situación a todas luces insatisfactoria, nos gustaría aportar una visión distinta acerca de tan espinosa cuestión. Para ello, consideramos necesario retroceder unos pasos para obtener una perspectiva más global del debate, situándolo en toda su justa dimensión diacrónica, y para ello aumentaremos al máximo posible su marco de desarrollo temporal. Se trataría, en suma, de poder conocer la opinión sobre el tema de los propios griegos y romanos, puesto que hablamos, al fin y al cabo, de su mitología, para cuyo estudio, además, poseían ya algunas de las disciplinas científicas necesarias. De ser así, nos situaríamos a la mayor distancia posible de la actual controversia, en los inicios mismos de la misma, y dispondríamos, en definitiva, de un punto de vista más amplio y adecuado. Al mismo tiempo, se nos ofrece una oportunidad excelente para contemplar cómo la filología antigua abordó un caso de estudio paradigmático, lo que nos permite conocerla y apreciarla mejor, tanto a partir de sus aciertos como de sus limitaciones.

Cabe entonces preguntarse si semejante debate se planteó ya en la Antigüedad $\mathrm{y}$, en caso afirmativo, cómo se desarrolló, quiénes participaron, con qué datos y métodos contaron o qué soluciones aportaron. No resulta fácil contestar a estas preguntas, por una sencilla razón: las fuentes primarias de información se han perdido por completo. Lamentablemente, la inmensa producción filológica de la Antigüedad, hecha al amparo de los grandes centros de estudio en Alejandría, Pérgamo, Atenas o Roma, no sobrevivió al largo y complicado proceso de la transmisión textual. Todo lo más, disponemos de escasísimos restos, procedentes en su gran mayoría de fuentes secundarias: escolios, léxicos y comentarios (es decir, compilaciones de época muy posterior, que extractan y resumen los trabajos originales), y alguna que otra cita breve en obras de autores clásicos.

10 Algunas de las otras propuestas en Gelinne (1988: 227-228) y en Martínez Hernández (2005: 33-42).

11 Así, por ejemplo, la explicación de Burkert (1965), que parece ser de las más aceptadas hoy en día, ha sido refutada por Beekes (1998), quien propone una nueva etimología, la más reciente hasta la fecha. 
Con este desalentador panorama, no es de extrañar que la propia existencia de un debate grecolatino sobre el origen de los Campos Elisios haya pasado desapercibida para la posteridad. Quizás por ello, durante el siglo y pico que la filología actual lleva estudiando la cuestión del origen, casi ningún investigador se ha referido a sus predecesores grecolatinos. Aparte de una breve nota a pie de página de Rhode (1894: 76, nota 2) y un breve párrafo de Gelinne (1988: 227) no fue hasta 1992 cuando, gracias a un libro de M. Martínez, la investigación sobre los Campos Elisios en el mundo antiguo se estudia por vez primera, de forma resumida. En su trabajo se recopilan y comentan las principales propuestas etimológicas recogidas en los textos supervivientes (revelando que hay, al menos, constancia documental para abordar el tema), y se establece el marco teórico y práctico en el que se basa nuestra propia aportación, que está concebida como continuación y ampliación de dicho trabajo.

Por consiguiente, nuestro objetivo es recorrer hasta el final esta vía de investigación, para sacar a la luz todo lo que nos es posible conocer acerca de la cuestión del origen de los Campos Elisios en la Antigüedad. Intentaremos esclarecer si realmente lo estudiaron en profundidad, si se llegó incluso a generar todo un debate científico al respecto y, en tal caso, qué investigadores o qué escuelas intervinieron en el mismo, con qué fin lo hicieron, qué metodología emplearon, y a qué soluciones llegaron. El propósito último sería poder demostrar que existe una relación entre esa supuesta controversia de los sabios griegos y romanos y la de los investigadores de hoy en día.

La metodología adoptada consiste, esencialmente, en seguir las huellas y señales que la controversia ha dejado en los restos textuales conservados. Para ello, empezamos por recopilar el corpus completo de fuentes disponibles, que son de dos tipos. En el primero, que abarca la mayor parte, incluimos los testimonios que se usan habitualmente en la investigación acerca de la filología helenística y romana: al carecer de las fuentes primarias, la información que contenían solo se puede obtener de fuentes secundarias de un período histórico posterior, es decir, de época bizantina (s. VI - XIV d.C.), que son nuestra única vía de acceso a la producción de siglos anteriores $^{12}$. Por fortuna, disponemos también de un segundo tipo, menos numeroso, compuesto por fuentes secundarias verdaderamente antiguas, de tiempos grecorromanos. Las fuentes del primer tipo son valiosas, porque extraen su información de aquellas obras y autores que aún se conservaban por entonces (y que, en muchos casos, incluso citan expresamente). Las del segundo, como es natural, tienen mayor valor aún, porque son más inmediatas y pueden contribuir a confirmar los datos suministrados por los textos bizantinos. Por esta razón, presentaremos los testimonios en orden de menor a mayor antigüedad, provistos además de la correspondiente versión en español (varios de ellos no disponen de traducción a ninguna lengua moderna).

A continuación, seleccionamos y comentamos todas las diferentes explicaciones acerca del origen de los Campos Elisios. En cada una de ellas procuramos extraer el máximo de información pertinente, mediante su análisis interno o acudiendo, si es posible, a la comparación con otros textos. Los resultados obtenidos se discutirán posteriormente en relación con los objetivos previstos: abordamos las evidencias que permiten establecer la existencia de un verdadero debate científico sobre la cuestión, y a partir de ellas intentamos además hacer una reconstrucción de las líneas principales del mismo; también se organizan y analizan los datos relativos a los autores

12 Para esta cuestión resultan imprescindibles las dos guías introductorias de Dickey (2007 y 2015), con bibliografía muy actualizada, y Serrano Aybar (1977). 
o escuelas y su labor filológica; y, por último, se comparan estos datos con otros procedentes del debate actual.

Las fuentes de época bizantina son siete en total. Como es habitual en estos casos, su contenido es bastante homogéneo, bien porque extractan de las mismas obras clásicas o porque unas más antiguas han servido de fuente a otras más recientes. Parar facilitar su disponibilidad, hemos extraído los textos del Thesaurus Linguae Graecae, donde pueden consultarse los datos acerca de las ediciones utilizadas. En orden de menor a mayor antigüedad son los siguientes:

\section{Lexicon atribuido a Nicéforo Gregoras (s. XIV d.C.)}

'H

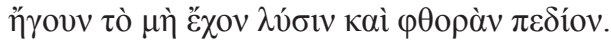

La Llanura Elisia es el paraíso de los griegos, del verbo disolver y la alfa privativa, creían que era una llanura sin disolución ni destrucción.

\section{Etymologicum Magnum (s. XII d.C.)}

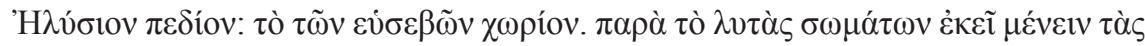

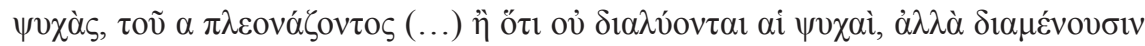

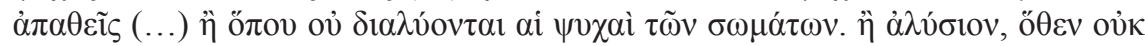

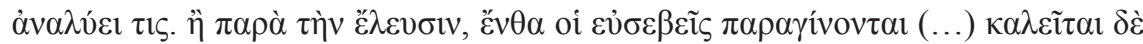

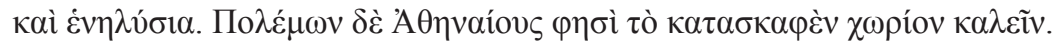

Llanura Elisia: el lugar de los piadosos, porque las almas se quedan allí desligadas de sus cuerpos, siendo la alfa inicial un añadido (...) o porque no se disuelven las almas, sino que permanecen sin daños (...) o porque no se separan las almas de sus cuerpos; o de indestructible, porque no se destruye nadie; o por el sitio de ida donde se hayan los piadosos (...) se le llama también enelisio, y Polemón dice que se llama así al sitio golpeado por un rayo.

\section{Eustacio de Tesalónica (s. XII d.C.)}

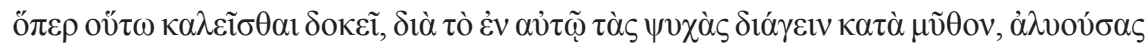

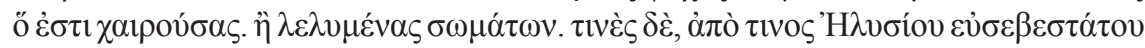

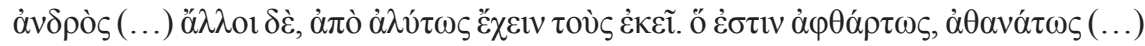

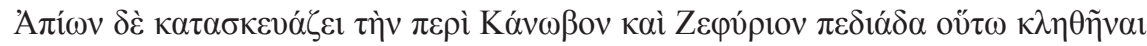

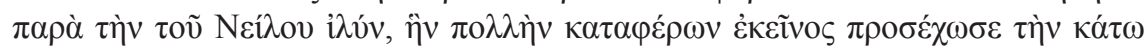

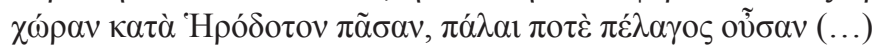

Este parece llamarse así porque en él las almas viven según el mito, es decir, alegres y felices; o separadas de sus cuerpos; otros dicen que por un tal Elisio, hombre de gran piedad (...) otros dicen que es porque los que están allí son indisolubles, es decir, indestructibles e inmortales (...) Apión explica que se llamó así a la llanura 
existente por la zona de Canobo y Zefirio, debido a las marismas del Nilo, formadas por la tierra que el río transporta en gran cantidad hasta amontonar al final todo aquel territorio que, según Heródoto, en otro tiempo fue mar.

\section{Léxico Suda (s. X d.C.)}

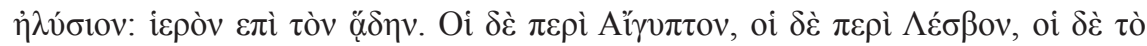

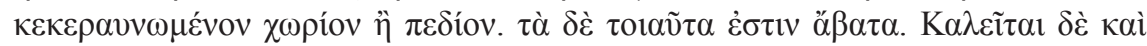
$\dot{\varepsilon} \vee \eta \lambda u ́ \sigma 1 \alpha$.

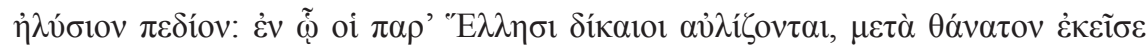
$\dot{\varepsilon} \lambda \varepsilon v \sigma o ́ \mu \varepsilon v o 1$

Elisio: sitio sagrado en el Hades. Unos dicen que estaba por Egipto, otros por Lesbos, otros que es un sitio o una llanura donde ha caído un rayo (este tipo de sitios son sagrados, y se les llama también enelisios).

Llanura Elisia: donde viven los que eran justos en la antigua Grecia, porque se iban allí después de la muerte.

\section{Lexicum Gudianum (s. X d.C.)}

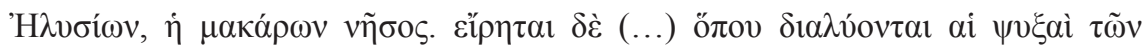

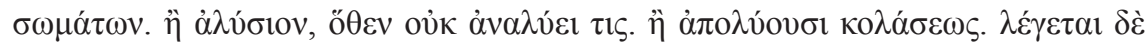
'H

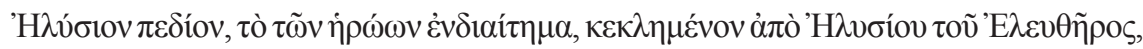

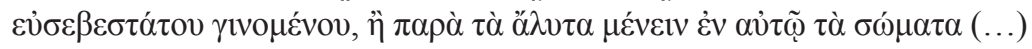

Elisio: la Isla de los Afortunados; se llama así (...) porque las almas se separan de sus cuerpos; o de indestructible, porque no se destruye nadie; o porque se libran del castigo; también se llama Elisio una llanura sagrada de Rodas; unos dicen que estaba por Egipto, otros por Lesbos.

Llanura Elisia: la residencia de los héroes, llamada así por Elisio, hijo de Eleuter, que fue un hombre de gran piedad, o porque en él los cuerpos permanecen indestructibles.

\section{Léxico Haimodein (s. IX-X d.C.)}

'H

Elisio: (...) porque las almas se separan de sus cuerpos.

\section{Escolios antiguos (s. IX-XI d. C.)}

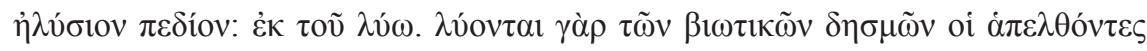

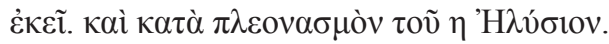


Llanura Elisia: del verbo soltarse, porque los que se marchan allí se sueltan de las ataduras vitales, y con una eta de añadido.

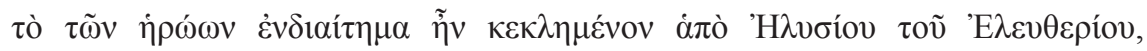

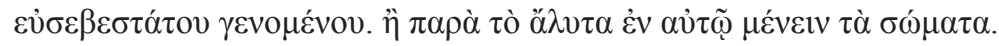

La residencia de los héroes se llamaba así por Elisio, hijo de Eleuterio, que fue un hombre de gran piedad, o porque en él los cuerpos permanecen indestructibles.

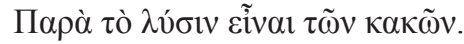

Por la liberación de las desgracias.

Las fuentes de época grecorromana son en total cinco. Aunque en general no discrepan de los datos de las fuentes bizantinas, son sin duda algo diferentes de ellas: por ejemplo, tienden a decantarse por una sola explicación, lo que es coherente con su naturaleza, menos enciclopédica. Aquí también se presentan en orden de menor a mayor antigüedad

\section{Pseudo-Nonno (s. VI d.C.)}

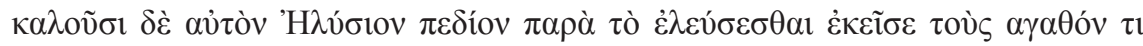
$\beta \varepsilon \beta 1 \omega \kappa o ́ \tau \alpha \varsigma$.

Lo llaman Llanura Elisia porque allí se irán los que han llevado una vida de bien

\section{Hesiquio (s. V-VI a.C.)}

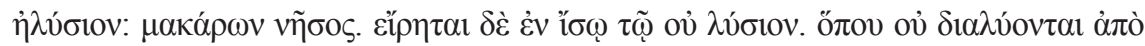

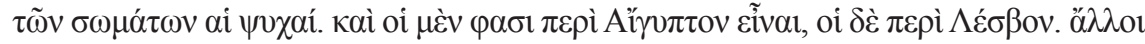

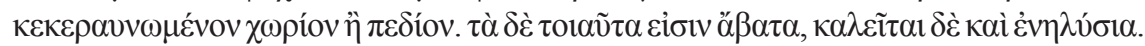

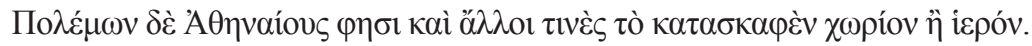

Elisio: Isla de los Afortunados. Se dice así por ser igual a no separable, ya que allí no se separan las almas de sus cuerpos. También dicen algunos que está por Egipto, otros que por Lesbos. Otros, que es un sitio o una llanura donde ha caído el rayo (los sitios así son sagrados, y se les llama también enelisios). Polemón, junto con algunos otros, dice que son los atenienses los que llaman así al sitio o al santuario golpeado por el rayo.

\section{Estobeo (s. V d.C.), cita de Porfirio de Tiro}

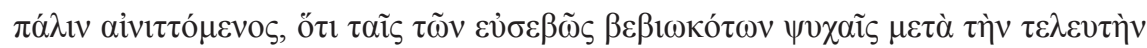

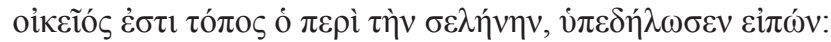

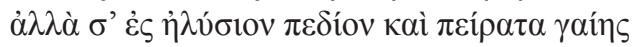

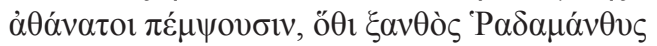

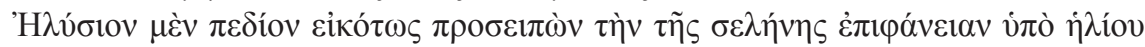
$\kappa \alpha \tau \alpha \lambda \alpha \mu \pi \mathrm{\circ} \mu \dot{\varepsilon} \vee \eta v$. 
Una vez más, queriendo hacernos adivinar por medio de enigmas que las almas de los que han vivido piadosamente tienen como residencia después de la muerte un lugar en la luna, lo dejó entender diciendo "sino que los inmortales te enviarán a la Llanura Elisia y los confines de la Tierra, donde el rubio Radamantis", denominando con toda propiedad Llanura Elisia a la cara de la luna iluminada por el sol.

\section{Orígenes (s. IV d.C.)}

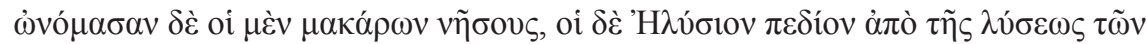

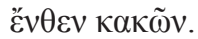

Unos lo denominaban Islas de los Bienaventurados, otros, Llanura Elisia, por la separación de los males de esta vida.

\section{Servio (s. IV d.C.)}

Elysium est ubi piorum animae habitant post corporis animaeque discretionem: unde et 'interitus' dicitur res 'inter' animam et corpus 'veniens'. Ergo Elysium ḋ $\pi \dot{o}$ $\tau \tilde{\eta} \varsigma \lambda v \sigma \varepsilon \omega \varsigma$, ab absolutione (...) Secundum philosophos Elysium est insulae fortunatae, quas ait Sallustius inclitas esse homeri carminibus (...) Secundum theologos circa lunarem circulum (...)

El Elisio es donde viven las almas de las personas piadosas después de la separación del cuerpo y el alma. Por eso se llama muerte a lo que se mete entre el alma y el cuerpo. Por tanto, Elisio viene del griego lysis, es decir, separación (...) Según los filósofos el Elisio es lo mismo que las Islas de los Afortunados, que dice Salustio son famosas por los poemas de Homero (...) Según los teólogos está alrededor del círculo de la luna (...).

En este punto de nuestra exposición se puede comprobar que, como decíamos al empezar, solo unos escasos restos se han conservado acerca de nuestro objeto de estudio: muy pocos textos, y para colmo muy breves, con una extensión que va de una simple línea a, todo lo más, un pequeño párrafo. Además, la cantidad de información que proporcionan se ve restringida por un hecho evidente: muchos no hacen sino repetir los mismos contenidos. Sin embargo, los datos suministrados nos permiten conocer todo un conjunto de explicaciones acerca del origen de los Campos Elisios. A continuación, intentaremos establecer cuántas y cuáles son, y explicar sus características principales.

Lo primero que llama nuestra atención es la existencia de un grupo de explicaciones con un denominador común: todas derivan el término ì $\lambda \hat{\sigma} \sigma$ tov de la raíz del verbo $\lambda \hat{v} \omega$ ('disolver, separar, liberar' > 'destruir'). Da la impresión de que esta derivación es la que cuenta con mayor éxito, ya que es la que se repite en una mayor cantidad de fuentes: aparece en nueve de las doce (testimonios 1, 2, 3, 5, 6, 7, 9, 11,12 ); además, es la única seleccionada en dos (los números 11 y 12) de los cinco testimonios de época grecolatina (que, como señalábamos antes, suelen mostrar un menor afán enciclopédico que los autores bizantinos). Estos datos parecen apuntar a 
que se trata de la derivación más aceptada. Sin embargo, hay que precisar que esta línea de explicación no es en absoluto unitaria, pues ha dado lugar a unas cinco o seis etimologías diferentes:

1. Separación del cuerpo y el alma (testimonios $2,3,5,6,12$ ).

2. Separación de (los males de) la vida $(7,11)$.

3. Separación de los castigos del más allá (5).

4. No separación del cuerpo y el alma $(2,9)$.

5. Inmortalidad del alma (2).

6. Inmortalidad de cuerpo y alma, de la persona $(1,2,3,5,7)$.

No cabe duda de que resulta, cuanto menos, sorprendente el interés que muestran los filólogos antiguos por establecer alguna forma de derivación de esta raíz en concreto, que da la impresión de responder más a una especie de fijación que a una simple predilección. La sorpresa es mayor si tenemos en cuenta que no existen razones objetivas para semejante preferencia, sino todo lo contrario. En primer lugar, por el plano de la expresión, no cabe pensar que la palabra ì $\lambda$ v́oıv se asociara fonéticamente de manera clara e inmediata con la palabra $\lambda \hat{v} \omega$ : cualquier hablante percibiría que semejante asociación podía establecerse única y exclusivamente con una de las dos sílabas del radical, la interior ( $(\lambda v-)$, dejando la otra al margen, la inicial $(\eta-)$; los propios autores griegos nos suministran pruebas de que la asociación fonética no conseguía funcionar del todo por este motivo, puesto que, en su afán por defenderla, intentan en más de una ocasión ofrecer alguna justificación para esa incómoda sílaba, acudiendo a argumentos nada convincentes, bien para cualquier hablante competente (p.ej. el testimonio 9 la equipara con la negación oủ), bien para uno con conocimientos especializados (p.ej. el testimonio 1 la iguala con una alfa privativa). En segundo lugar, por el plano del contenido, no existe una más o menos precisa adecuación entre el significado básico de la raíz $* \lambda v$ - y el sentido que poseen los Campos Elisios en el contexto de la mitología griega, como evidencia el simple hecho de que haya que recurrir a tantas explicaciones distintas para lograr encajar el uno con el otro. Por consiguiente, debe haber una razón de otra índole que explique tan desmedido interés por establecer, sea como sea, una derivación a partir de $\lambda v ́ \omega$, llegando incluso al extremo de proponer hasta media docena de etimologías (y ninguna satisfactoria).

En nuestra opinión, la causa más probable podría ser el prestigio y la influencia del creador de tal línea de explicación, o del creador de las ideas o argumentos en que está basada. A la vista está que nuestro corpus de fragmentos no nos da noticia alguna del autor o autores de este conjunto de etimologías; pero, respecto al argumentario que se emplea en dichas etimologías, la cosa es bien distinta, porque hay un texto muy conocido, en una de las obras más importantes de Platón, que aporta un planteamiento fundamental para poder establecer una relación entre los Campos Elisios y el verbo $\lambda \hat{\omega} \omega$ :

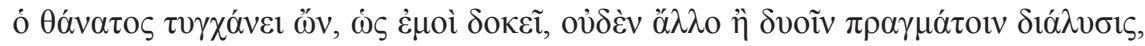
$\tau \tilde{\eta} \varsigma \psi v \chi \tilde{\eta} \varsigma \kappa \alpha i ̀ ~ \tau o \tilde{~} \sigma \omega ́ \mu \alpha \tau o \varsigma, \dot{\alpha} \pi ’ \dot{\alpha} \lambda \lambda \hat{\eta} \lambda$ ovv.

En mi opinión, la muerte no es otra cosa que la separación de dos cosas, el alma y el cuerpo, una de otra. 
Aunque la concepción de la muerte como fin de la unión alma-cuerpo es una idea común en el pensamiento griego, que se encuentra ya desde los poemas homéricos, la formulación de tal idea en términos de $\delta i \alpha ́ \lambda v \sigma i \varsigma$ es típicamente platónica, porque se refiere a uno de los puntos principales de su doctrina escatológica: la visión del cuerpo como una cárcel $(\sigma \tilde{\omega} \mu \alpha-\sigma \tilde{\eta} \mu \alpha)$ de la que el alma, con la muerte, se libera (es el sentido que aquí tiene $\lambda \hat{v} \omega)$ para ascender a una vida mejor. En el caso de nuestro bizarro grupo de seis etimologías, hay una en concreto que reproduce literalmente este pasaje de Platón: la que hemos consignado en primer lugar y que, por añadidura,

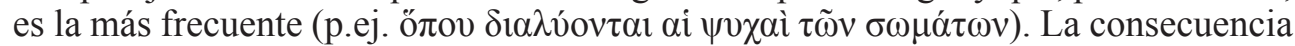
lógica es que esta etimología debió crearse en el ámbito de la escuela platónica, donde, como es sabido, la investigación etimológica jugaba un papel central (como se ve en varios diálogos de Platón, y muy especialmente en el Cratilo). Se trata, pues, de una investigación del sentido original de los Campos Elisios dotada de un indudable prestigio, lo que explicaría su aparente éxito. Y de todo el grupo de etimologías derivadas de $\lambda v ́ \omega$, tuvo que ser, además, la primera en aparecer, porque la mejor forma de explicar las otras cinco es verlas como reacción a ella (todas intentan corregir esa falta de adecuación al mito que indicábamos antes, que en este caso es total), lo que explicaría tan absurda proliferación.

Otra etimología que parece haber gozado de amplia difusión (se recoge en tres testimonios, los números 2,4 y 8) es la que relaciona †̉ cipal verbo de movimiento, *'่ $\lambda v \theta$ - 'ir, venir'. Tal como ocurría en el caso anterior, no es una explicación del todo unitaria: al parecer, había quienes la entendían en un sentido ('el lugar de la ida' > 'el lugar de destino final') y quienes en otro ligeramente distinto ('el lugar de los que se han ido, de los muertos'), aunque se trata de una mera diferencia de matiz. Esta derivación es, a todas luces, mucho más satisfactoria, en todos los sentidos: hay una gran correspondencia desde el punto de vista fonético, y el significado se adecua al mito a la perfección. Tanto es así, que ha logrado mantenerse como una explicación plenamente válida hasta tiempos modernos: así, por ejemplo, todavía Rhode (v. nota 6) consideraba que los Campos Elisios eran la Land den hingegangenen, y también figura en varias obras clásicas de nuestra especialidad, como el Pauly-Wissowa (Land der Hinkunft) o el Preller-Robert. Por tanto, podemos considerarla como un legado del debate antiguo al debate moderno, o lo que es lo mismo, una prueba inequívoca de que existe una conexión entre ambos debates. Desgraciadamente, no disponemos de dato alguno sobre el autor ni la época de creación, aunque podemos estar seguros de que existió ya, en época grecolatina, por las fechas del testimonio número 8.

Mucho más seguros son, sin embargo, los datos acerca de otra propuesta de explicación que también disfrutó de gran aceptación, pues también se recoge en tres de los testimonios (los números 2, 4 y 9). Esta etimología establece la derivación a partir del nombre que se daba a algunos lugares considerados sagrados por haber caído en ellos un rayo, los denominados enelisios; si la correspondencia con el sentido original del espacio mítico resulta del todo satisfactoria (Campos Elisios significaría 'campos sagrados'), también desde el punto de vista lingüístico la relación es

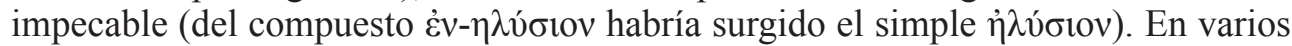
sentidos, esta propuesta responde a un tipo de investigación diferente, de mayor calidad y de una concepción mucho más moderna que las demás, ya que en ella se combina la labor puramente lingüística con la recogida y análisis de datos auténticamente científicos, provenientes de un genuino trabajo de campo. Los eruditos, tanto 
los bizantinos como los grecolatinos, parecen haber sido conscientes de este mayor nivel de la explicación, como lo demuestra el hecho de que pongan especial empeño en darnos el nombre de su creador: un autor de época helenística, que conocemos por otras fuentes, llamado Polemón de Ilión (s. II a.C.), del que consta su relación con la escuela de Pérgamo11. Nos encontramos aquí, pues, con uno de los poquísimos casos de etimología con autoría reconocida y datable con plena seguridad, lo cual lo hace, como es natural, especialmente útil para nuestra investigación. Por lo pronto, con los escasos datos disponibles, es la explicación más antigua de todas las transmitidas, y permite afirmar que la cuestión del origen de los Campos Elisios fue abordada por una de las primeras escuelas filológicas helenísticas, la de Pérgamo, y de acuerdo con unos métodos científicos muy avanzados. De hecho, su calidad es tal que la etimología del sabio Polemón ha sido actualizada recientemente por el investigador de la religión griega más famoso de la actualidad, Burkert (1985), y es quizás una de las más aceptada hoy en día, lo que aporta otra prueba más de la conexión entre el debate antiguo y el moderno.

De interés parecido es la propuesta que transmiten parcialmente los testimonios número 4,5 y 9 , y que recoge por extenso el número 3 . La explicación parte también de una evidencia científica, hoy confirmada por los egiptólogos: que en Egipto se consideraban sagradas las llanuras pantanosas del delta del Nilo (porque, según una creencia atestiguada desde los primeros textos, estaban consagradas al dios Osiris y en ella residían las almas); por contra, la prueba lingüística resulta endeble, puesto

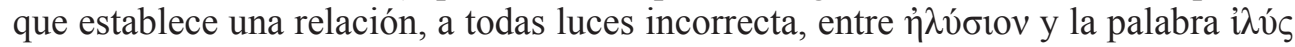
'pantano, marisma', fruto de la pronunciación itacista del griego post-clásico. A pesar de esta deficiencia, hay que destacar que esta explicación del origen de los Campos Elisios opera de una forma muy similar a la de Polemón, combinando la recogida de datos objetivos y la lingüística, y apunta igualmente a un tipo de investigación de mayor calidad que el de otras propuestas. Quizás por ello ha disfrutado de mejor valoración y mayor prestigio, y por eso encontramos de nuevo, como en el caso de Polemón, que, al menos, una de las fuentes considere necesario consignar el nombre de su autor, que es, precisamente, un erudito de origen egipcio: Apión de Alejandría (c. 20 a.C. $-45 / 48$ d.C.). Todo esto nos sirve para confirmar la implicación de la principal institución investigadora de la filología antigua, el Museo de Alejandría, en el debate. Disponemos de un indicio adicional del alto nivel científico de Apión y su escuela: su teoría del origen egipcio de los Campos Elisios ha sido reformulada por investigadores actuales (Alford, 1987) y goza de amplia aceptación, lo que demuestra, una vez más, que el debate antiguo y el moderno están interconectados.

También tiene una indudable utilidad para nuestro estudio la explicación que transmite una única fuente, el testimonio número 10. En este caso, se trata de una propuesta muy diferente de las dos anteriores, por su escaso interés en seguir la metodología científica de la época. De hecho, no nos encontramos ahora ante la labor de un hombre de ciencia, sino más bien ante una profesión de fe. Esta etimología se basa en las creencias sobre el más allá de las múltiples y heterogéneas corrientes filosófico-religiosas que suelen agruparse bajo el nombre de neoplatonismo, que hicieron furor en tiempos tardíos del mundo antiguo y que dejaron su impronta en el por entonces naciente cristianismo. Los creyentes en estas doctrinas escatológicas pensaban que, tras la muerte, las almas de los fieles iban a la luna, donde experimentaban, en una especie de purgatorio, un proceso de purificación de los restos de su existencia terrenal, como paso previo y necesario para ascender a su destino definiti- 
vo, las esferas celestiales. Ni que decir tiene que esta residencia lunar de las almas no tiene ninguna relación con la función original de los Campos Elisios; pero las nuevas tendencias religiosas de época tardía buscaban conferir a sus innovadoras creencias el prestigio de los mitos antiguos, por lo que no tenían reparos en asimilar las unas con los otros, creando así la equiparación de su novedoso destino escatológico con los tradicionales Campos Elisios (Buffiere 1973: 490-498). En este caso concreto, la

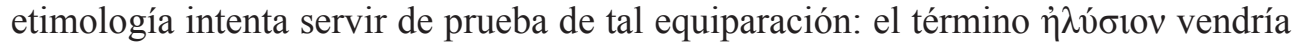
entonces de ī $\lambda \iota_{0} \varsigma$ 'sol', porque se refiere a la cara de la luna iluminada por el astro rey. La explicación, aparte de chocante, presta tan poca atención al plano de la expresión como la que tenía con el contenido; pero la consideramos muy interesante por una razón: nos indica que en el debate sobre la cuestión del origen participó también el movimiento neoplatónico, al que pertenecía, según varias fuentes, el autor del texto citado por el testimonio: Porfirio de Tiro (232-304 d.C.).

Para terminar, los testimonios de nuestro corpus recogen algunas propuestas explicativas más, que se repiten incluso en varios de ellos, pero de los que se ofrece muy escasa información. Hay una que fundamenta el término en el nombre de un personaje mítico, Elisio, hijo de Eleuter o Eleuterio, del que no tenemos constancia alguna por ninguna otra vía, y que da la impresión de tratarse de un caso típico de

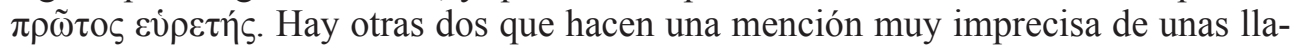
nuras en Rodas y en Lesbos, de las que, por desgracia, no se nos aporta más información.

En suma, esperamos que el análisis de los datos suministrados por nuestro corpus de testimonios haya permitido alcanzar los objetivos planteados en la introducción del artículo. Ante todo, creemos que ha quedado de sobra demostrado que la filología de los períodos helenístico y romano trató por extenso la cuestión del origen de los Campos Elisios. Así lo atestigua la gran cantidad de explicaciones propuestas, que alcanza un total de doce en los textos transmitidos, lo que hace suponer, debido al estado ruinoso de conservación, que debió haber algunas más. A pesar de los problemas de datación que presentan siempre este tipo de fuentes secundarias y tardías, en este caso tenemos la fortuna de poder confirmar que la investigación del tema se remonta, al menos, al siglo II a.C., y que prosiguió sin interrupción en siglos posteriores (de los que poseemos algunas fuentes) hasta llegar a los eruditos de época bizantina, que las recogieron en las mejores producciones de esa etapa de la historia de la filología (Etymologicum Magnum, Suda, etc.). También nos parece confirmarse por completo el objetivo central de este trabajo: la cuestión generó un amplio e intenso debate, que ha dejado numerosos indicios en los restos textuales. Así lo indica, por ejemplo, la propia proliferación y acumulación de hipótesis explicativas en un mismo resumen, que es la tónica dominante en la gran mayoría de los testimonios; sin duda, debemos considerarla como un registro razonablemente fiable de un estado de controversia, de un proceso dinámico y en ebullición, en el que ninguna hipótesis llega a ser concluyente y definitiva, y donde la cuestión, por tanto, permanece abierta a la discusión. Hay incluso señales que apuntan a la intensidad de una auténtica polémica, con posturas muy enfrentadas e irreconciliables entre sí: por ejemplo, el caso de las etimologías a partir de $\lambda u ́ \omega$ es muy revelador al respecto, con sus frecuentes explicaciones de signo opuesto (se disuelven / no se disuelven); pero también parece significativo en este sentido el hecho de que algunos de los resúmenes adopten una estructura algo caótica y aporten contenidos contradictorios e incompatibles entre sí; otros, en un lógico intento de 
ordenar y sistematizar las posturas opuestas, recurren a las estructuras sintácticas que expresan división de opiniones (oi $\mu \varepsilon \grave{\varepsilon}$... oi $\delta \varepsilon ́$, secundum $X \ldots$ secundum $Y$ ) o, aún mejor, definen expresamente los grupos contrarios (p.ej. philosophos / theologos en Servio). Si tales indicios han logrado sobrevivir a la total destrucción de las obras de los autores originales, transmitiendo una mera impresión de activo y encendido debate, no nos cabe duda de que el origen de los Campos Elisios pudo ser una de las grandes discusiones de la filología antigua.

Por último, y no menos importante, nuestro estudio ha conseguido desenterrar de las ruinas y sacar a la luz los elementos fundamentales que conforman dicho debate. Advertimos, por ejemplo, que hubo varias líneas de investigación: algunas de gran calidad científica, y que han dado el salto a la tradición posterior y siguen en activo; otras de mucha menor o ninguna, y que por ello han quedado con el tiempo arrinconadas en el desván de los trastos viejos. También sabemos que la metodología predominante es la misma que se ha consagrado en tiempos modernos, y que tiene en la investigación etimológica su eje central; pero también, que hay variantes al respecto, ya que puede emplearse de distintas maneras (con trabajo de campo o sin él, mediante método comparativo...) y, claro está, con eficacia muy diversa. Asimismo, tenemos la gran suerte de acceder al conocimiento de varios de los participantes, con resultados muy importantes al respecto: hemos identificado incluso figuras concretas, como Polemón de Ilión, Apión de Alejandría o Porfirio de Tiro, pero, sobre todo, hemos establecido la implicación de los grandes centros investigadores de la Antigüedad, desde las bibliotecas de Alejandría y Pérgamo hasta varias de las diversas escuelas herederas de la Academia platónica ( como el platonismo tardío y el neoplatonismo). Es decir, la cuestión recibió aportaciones de muy diversos ámbitos de la cultura clásica, desde las ciencias y la filosofía hasta la religión.

Como conclusión, solo nos queda señalar que hemos mostrado que la cuestión del origen de los Campos Elisios presenta numerosas y evidentes conexiones entre la Antigüedad y el presente. Podemos afirmar que se trata, de hecho, de un mismo y único debate en sucesivos estadios de desarrollo. No solo ha influido el debate antiguo sobre el moderno, sino que además el primero sentó las bases sobre los que se erige el segundo, condicionando así, en gran medida, todo su desarrollo posterior hasta su resultado actual. Entonces, la consecuencia lógica sería admitir que hoy nos encontramos tan solo en una fase de un proceso diacrónico mucho más amplio, y que quizás estamos, simplemente, envueltos (y, aún peor, atascados) en una interminable polémica, no ya de siglos, sino de milenios.

\section{Bibliografía}

Alford, Garth, (1987), The Origin and Employment of a Foreign Eschatological Concept in Archaic Greek Literature. diss. University of Washington.

Beekes, Robert S. P. (1998), "Hades and Elysium" en J. Jasanaff e al.(eds.), Mir Curad. Studies in Honour of Calver Watkins. Insbrück, 17-28.

- (2010), Etymological Dictionary of Greek, vol. I. Leiden-Boston: Brill.

Buffiere, Félix (1973), Les mythes d'Homère et la pensée grecque. París: Les Belles Lettres. Burkert, Alfred (1961), "Elysion", Glotta 39, 208-213.

Chantraine, Pierre (1970), Dictionnaire étymologique de la langue grècque, vol. II. París: Klincsieck. 
Dickey, Eleanor (2007), Ancient Greek Scholarship: a Guide to Finding, Reading, and Understanding Scholia, Commentaries, Lexica and Grammatical treatises: from their Beginnings to the Byzantine Period. Oxford: Oxford University Press.

- (2015), "The Sources of our Knowledge of Ancient Scholarship" en F. Montanari et al. (eds.), Brill's Companion to Ancient Greek Scholarship, Leiden, 459-514.

Dirlmeier, Franz (1955), "Homerisches Epos und Orient”, RhM. 98 (1955), 18-37.

Gelinne, Michel (1988), "Les Champs Élysées et les Iles des Bienheureux chez Homère, Hésiode et Pindare. Essai de mise au point". LEC 56, 225-240.

Malten, Ludwig (1913), "Elysium und Rhadamanthys", JDAI (28), 35-51.

Martínez Hernández, Marcos (1992), Canarias en la mitología. Sta. Cruz de Tenerife: Centro de la Cultura Popular Canaria.

- (2005), La mitología. Todo sobre Canarias. Sta. Cruz de Tenerife: Centro de la Cultura Popular Canaria.

Matthaios, Stephanos (2015), "Greek Scholarship in the Imperial Era and Late Antiquity" en F. Montanari et al. (eds.), Brill's Companion to Ancient Greek Scholarship, Leiden, 184-296.

Montana, Fausto (2015), "Hellenistic Scholarship” en F. Montanari et al. (ed.), Brill's Companion to Ancient Scholarship, Leiden, 60-183.

Nilsson, Martin P. (1955²), Geschichte der griechischen Religion, Múnich: C.H. Beck.

Pontani, Philippomaria (2015), "Scholarship in the Byzantine Empire (529-1453) en F. Montanari et al. (eds.), Brill's Companion to Ancient Scholarship, Leiden, 297-455.

Puhvel, Jan (1969), "Meadow of the Otherworld in ie. Tradition", KZ 83, 64-69.

Rhode, Erwin (1894), Psykhe. Seelencult und Unsterblichkeitsglaube der Griechen. Friburgo-Leipzig: Mohr.

Serrano Aybar, Concepción (1977), "Historia de la Lexicografía griega antigua y medieval" en F. Rodríguez Adrados et al., Introducción a la lexicografía griega, Madrid.

Sourvinou-Inwood, Christiane (1995), Reading Greek Death. To the End of the Classical Period. Oxford: Oxford University Press.

Velasco López, María del Henar (2000), El paisaje del más allá. El tema del prado en la escatología indoeuropea. Valladolid: Secretariado de Publicaciones e Intercambio Editorial, Universidad de Valladolid.

Vermeule, Emily (1979), Aspects of Death in Early Greek Art and Poetry. Berkeley: University of California Press. 